\title{
Preparação de um material de referência certificado para controle de agrotóxicos em hortifrutigranjeiros: estudo da estabilidade
}

\author{
Preparation of a certified reference material for pesticide control \\ in the cultivation fruits and vegetables: a stability study \\ Maria Helena Wohlers Morelli CARDOSO ${ }^{1 *}$, Armi Wanderley da NÓBREGA ${ }^{1}$, \\ Hélio de Carvalho VITAL ${ }^{2}$, Shirley de Mello Pereira ABRANTES ${ }^{1}$
}

\begin{abstract}
Resumo
Neste trabalho são apresentados os resultados dos estudos de estabilidade referentes à produção de um material de referência certificado. Foram avaliados níveis residuais de concentração dos agrotóxicos $\gamma-\mathrm{HCH}$, fenitrotiona, clorpirifós e procimidona em polpa de tomate. A pasteurização e a irradiação gama foram empregadas à polpa de tomate, visando manter a integridade da amostra candidata a material de referência. A polpa foi preparada e dividida em duas partes. Cada parte foi fortificada com os referidos agrotóxicos na faixa de concentração de 0,1 a $0,2 \mathrm{mg} \cdot \mathrm{kg}^{-1}$. Uma das partes foi submetida à pasteurização a $90{ }^{\circ} \mathrm{C}$ por 4 minutos e a outra parte foi irradiada com dose de $2,0 \mathrm{kGy}$ depois de homogeneizada. A estabilidade e a incerteza da amostra, correspondente ao período de tempo avaliado, foram determinadas através da análise de regressão em conjunto com a ANOVA. Os resultados indicaram que ambos os procedimentos de preparo da amostra são adequados para a conservação da polpa de tomate fortificada com os quatro agrotóxicos, com vantagem para o tratamento por irradiação com a dose de $2,0 \mathrm{kGy}$.

Palavras-chave: agrotóxicos; material de referência; irradiação; pasteurização; estabilidade.
\end{abstract}

\begin{abstract}
This research presents the results of stability studies regarding the production of certified reference materials. The residual concentration levels of four pesticides, namely $\gamma-\mathrm{HCH}$, fenitrothion, chlorpyrifos, and procymidone were investigated. Pasteurization combined with gamma irradiation was used to maintain the integrity of the mixture tested as a reference material candidate. The pulp was prepared and split into two parts. Each part was then spiked with those pesticides in the concentration range of 0.1 to $0.2 \mathrm{mg} \cdot \mathrm{kg}^{-1}$ in tomato pulp. One of them was submitted to pasteurization at $90{ }^{\circ} \mathrm{C}$ for 4 minutes after being homogenized, and the other was irradiated with a gamma dose of $2.0 \mathrm{kGy}$. The material stability and the corresponding uncertainty during the period of time evaluated were determined using regression analysis and ANOVA. The results indicated that the dose of $2.0 \mathrm{kGy}$ was appropriated for the conservation of tomato pulp spiked with the four aforementioned pesticides.
\end{abstract}

Keywords: pesticides; reference material; stability test; irradiation; pasteurization.

\section{Introdução}

A constante busca em garantir a qualidade e confiabilidade de uma medição obtida através de ensaios analíticos é o alvo prioritário em laboratórios nos dias de hoje. Uma ferramenta indicada para este objetivo é o uso de materiais de referência, certificados ou não, que apresentam como características essenciais homogeneidade e estabilidade conhecida.

Cardoso (2008) apresentou os resultados referentes ao estudo da homogeneidade de um lote de polpa de tomate, candidata a material de referência certificado - MRC, fortificada com quatro agrotóxicos: $\gamma-\mathrm{HCH}$, fenitrotiona, clorpirifós e procimidona. Assim como a homogeneidade, a estabilidade é também pré-requisito no processo de certificação do material de referência, pois constitui um importante parâmetro, indicativo do grau de conservação do material durante períodos específicos de tempo e temperatura após a sua preparação. Sabe-se que o material preparado pode ser suscetível à degradação por ação de agentes tais como: tempo, temperatura, luz, oxigênio, umidade, atividade microbiológica entre outros (INTERNATIONAL ORGANIZATION FOR STANDARDIZATION, 2006).

O teste de estabilidade é mais complexo que o de homogeneidade. Para o estudo da estabilidade, devem ser considerados dois tipos de variação: de longa duração, que avalia a estabilidade do material, representando o tempo de estocagem ou de prateleira; e de curta duração, representando, por exemplo, as condições de transporte (van der VEEN et al., 2001; INTERNATIONAL ORGANIZATION FOR STANDARDIZATION, 2006).

O primeiro tipo é o modelo clássico, o qual mede o valor da propriedade da amostra em função do tempo. O período de monitoração das amostras baseou-se na expectativa de sua

Departamento de Química, Instituto Nacional de Controle de Qualidade em Saúde, Fundação Oswaldo Cruz - FIOCRUZ, Av. Brasil, 4365, CEP 21045-900, Manguinhos, Rio de Janeiro - RJ, Brasil, E-mail: helenawohlers@hotmail.com

${ }^{2}$ Divisão de Defesa Química, Biológica e Nuclear, Centro Tecnológico do Exército - CTEx, Av. da Américas, 28705, CEP 23020-470, Guaratiba, Rio de Janeiro - RJ, Brasil

${ }^{*}$ A quem a correspondência deve ser enviada 
vida útil, tipicamente entre 24 e 36 meses, correspondendo a 5 ou 6 intervalos típicos de amostragem. (INTERNATIONAL ORGANIZATION FOR STANDARDIZATION, 2006).

Como tal modelo deve ser executado sob condições de reprodutibilidade (concordância entre os resultados de medições de um mesmo mensurando sob condições variadas de medição) (BRASIL, 2007), o valor da incerteza inerente a essa característica - $u_{\text {lte, }}$ onde lte significa longo tempo de estocagem (van der VEEN et al., 2001), ou simplesmente $u_{\text {est }}$, deve ser também informado.

O estudo realizado em curto período de tempo é conhecido como isochronous design ou modelo isocrônico. Nesse modelo são realizadas, sob condições de repetitividade, medições simultâneas das amostras estocadas sob diferentes condições de temperatura, para produzir variações na taxa de deterioração dos agrotóxicos (LAMBERTY; SCHIMMEL; PAUWELS, 1998; van der VEEN et al., 2001; LINSINGER et al., 2001b; LINSINGER et al., 2004; INTERNATIONAL ORGANIZATION FOR STANDARDIZATION, 2006), ou seja, é possível através de uma única sequência de análise, utilizando a mesma curva analítica, realizar a avaliação dos resultados de medição sucessiva, levando a incertezas menores que aquelas decorrentes da utilização do modelo clássico e que, na maioria das vezes, podem ser negligenciadas. A extensão do tempo de estudo pode ser de dois meses, podendo se estender até seis a doze meses, visando-se obter informações adicionais sobre o tempo de estocagem (INTERNATIONAL ORGANIZATION FOR STANDARDIZATION, 2006).

O tomate foi o fruto matriz escolhido para ser o material de referência. Tomates são extremamente suscetíveis a danos por resfriamento, danos mecânicos e à presença de micro-organismos e, como este fruto apresenta teor de água elevado em sua constituição, consequentemente, há possibilidade de ocorrência de degradação dos agrotóxicos nessa matriz, decorrente de alguma atividade bacteriana que possa se desenvolver no meio, interferindo em sua estabilidade (SINGH et al., 2000; FLORES et al., 2004; MARTINS, 2006; COUTINHO et al., 2005).

Os processos térmicos ou físicos para fins de esterilização de alimentos constituem tecnologias empregadas na indústria para conservação de alimentos.

Dois exemplos de processo de esterilização, a pasteurização e a irradiação, são utilizados em indústrias de alimentos com o propósito de eliminar microrganismos, visando conservá-los, sem perda de suas qualidades e características nutricionais, durante o tempo de estocagem ou transporte (SILVA et al., 2006).

A pasteurização é um processo de tratamento capaz de inviabilizar o crescimento da maior parte das bactérias normalmente presentes no alimento, sem alterar suas propriedades ou características. Tradicionalmente, o processo caracteriza-se por um aquecimento do material a temperaturas entre 63 a $75^{\circ} \mathrm{C}$, por um período variável de 15 a 30 segundos, seguido por um resfriamento rápido sob temperaturas abaixo de $5^{\circ} \mathrm{C}$. Esse tratamento fornece uma eficiência bactericida superior a $98 \%$, podendo ser realizado em condições laboratoriais, ou seja, em pequena escala (GAVA, 1999).

A irradiação de alimentos, segundo a RDC n ${ }^{\circ} 21$ de 26 de janeiro de 2001, da ANVISA (BRASIL, 2001), é um processo físico de tratamento que consiste em submeter o alimento, já embalado ou a granel, a doses controladas de radiação ionizante, com finalidade sanitária, fitossanitária e ou tecnológica. Esse processo alternativo é capaz de prolongar a vida útil e melhorar a qualidade de vários tipos de alimentos, visando reduzir significativamente as perdas pós-colheita, além de aumentar a qualidade higiênica e a competitividade dos produtos agropecuários no mercado internacional.

A irradiação de alimentos pode ser vantajosa em relação à pasteurização porque atua com eficácia em todo o volume do produto sem elevar significativamente sua temperatura. Por outro lado, a pequena disponibilidade de irradiadores e a possibilidade da produção de alterações sensoriais, especialmente em doses mais elevadas, ainda constituem entraves para a utilização mais ampla da tecnologia (SILVA et al., 2006; SANT’ANA; ARAÚJO, 2007).

A ISO Guide 35 (INTERNATIONAL ORGANIZATION FOR STANDARDIZATION, 2006) estabelece que a avaliação da estabilidade do material seja feita pela análise de resíduos da regressão em conjunto com a análise de variância (ANOVA), que consiste em observar se a regressão linear dos valores de concentração dos analitos adicionados à amostra, ao longo do tempo apresenta alguma tendência. Se a inclinação da reta não for significativa, ou seja, se a concentração do agrotóxico não variar em função do tempo, o material é considerado estável (INTERNATIONAL ORGANIZATION FOR STANDARDIZATION 2006).

Os valores das concentrações dos analitos, obtidos ao longo do tempo, foram gerados pela utilização da cromatografia gasosa de alta resolução acoplada a detector por captura de elétrons (CGAR/DCE). Na análise qualitativa, empregou-se a cromatografia gasosa acoplada a detector seletivo de massas (CG/DSM), para detecção de substâncias desconhecidas na amostra (CARDOSO, 2008).

Este trabalho tem os objetivos de estudar e comparar dois tratamentos térmicos empregados para a produção da amostra visando garantir sua integridade durante o tempo de estocagem e sob condições de transporte. São apresentados os resultados da etapa referente à estabilidade (incluindo a incerteza) de um lote de polpa de tomate, submetido à radiação gama e à pasteurização, candidato a MRC, a ser utilizado na análise de resíduos de agrotóxicos. Os resultados encontrados neste estudo deverão indicar se a estabilidade da amostra é suficiente para que ela possa ser considerada um MRC.

\section{Material e métodos}

\subsection{Soluções de fortificação}

Foram utilizados padrões de agrotóxicos de pureza superior a 98\% (Dr. Ehrenstorfer; Riedel-de-Haën, Alemanha) com certificado de análise e solventes grau resíduos de pesticidas (Tedia, EUA). 
As soluções estoque individuais foram preparadas a partir da massa aproximada de $0,01 \mathrm{~g}$ do agrotóxico em naveta de vidro, quantitativamente transferida para balão volumétrico de $100 \mathrm{~mL}$. Os solventes de diluição para o $\gamma-\mathrm{HCH}$ e procimidona foram isoctano e acetato de etila para a fenitrotiona e clorpirifós, representando a concentração nominal de $100 \mu \mathrm{g} \cdot \mathrm{ml}^{-1}$. Para o preparo das soluções de fortificação individuais, a diluição foi realizada em acetona a partir das referidas soluções estoque.

Para a realização do Estudo piloto I - tratamento por pasteurização, as concentrações das soluções de fortificação foram 40,24 $\mu \mathrm{g} \cdot \mathrm{ml}^{-1}(\gamma-\mathrm{HCH}), 49,96 \mu \mathrm{g} \cdot \mathrm{ml}^{-1}$ (fenitrotiona), 49,66 $\mu \mathrm{g} \cdot \mathrm{ml}^{-1}$ (procimidona) e 47,92 $\mu \mathrm{g} \cdot \mathrm{ml}^{-1}$ (clorpirifós).

Novas soluções estoque de fenitrotiona e de clorpirifós foram preparadas para o Estudo piloto II - tratamento por radiação. Nesta situação as concentrações das soluções de fortificação foram 44,36 e 40,84 $\mu \mathrm{g} \cdot \mathrm{ml}^{-1}$ para a fenitrotiona e clorpirifós, respectivamente, e as demais não foram alteradas.

As concentrações de fortificação empregadas em ambos os estudos correspondem à faixa teórica aproximada de 0,1 a 0,2 mg. $\mathrm{kg}^{-1}$, de cada agrotóxico, na polpa de tomate.

\subsection{Preparo das amostras}

O tomate (orgânico) utilizado foi processado em um liquidificador após ser lavado, descascado e ter suas sementes retiradas. Em seguida, a polpa foi passada por peneira, com abertura de malha de $0,84 \mathrm{~mm}$.

Diante da preocupação de manter íntegra a polpa preparada, buscou-se o emprego dos dois tratamentos distintos, a pasteurização e a radiação gama.

Parte do lote preparado foi separada para o estudo do efeito da esterilização por processo de pasteurização (Estudo piloto I) e outra parte foi destinada ao tratamento por irradiação da polpa de tomate (Estudo piloto II).

As soluções de fortificação individuais, preparadas em acetona, foram adicionadas à polpa, homogeneizadas e envasadas em ampolas de vidro âmbar, de capacidade de $30 \mathrm{~mL}$. Contudo, antes de serem submetidas aos tratamentos específicos, objetivando manter a sua integridade, as amostra, tiveram sua homogeneidade confirmada, conforme apresentado por Cardoso (2008).

\section{Estudo piloto I - tratamento por pasteurização}

Preliminarmente, quatro ampolas do lote preparado para o Estudo piloto I, foram utilizadas para avaliar os efeitos da temperatura $\left(90{ }^{\circ} \mathrm{C}\right)$ e tempo (4 minutos) empregados no processo de pasteurização, conforme descrito a seguir.

As ampolas de vidro lacradas, contendo a polpa de tomate fortificada e o branco da polpa, foram submetidas ao tratamento térmico em banho a aproximadamente $90{ }^{\circ} \mathrm{C}$ por cerca de 4 minutos, seguido de banho de gelo para resfriamento rápido. Em seguida, as amostras preparadas, foram armazenadas em geladeira, freezer, estufa ou à temperatura ambiente, sob faixas de temperaturas descriminadas no planejamento experimental (item 2.5), para o estudo da estabilidade de estocagem.

\section{Estudo piloto II - tratamento por radiação}

Foram feitas avaliações preliminares dos efeitos da radiação gama, aplicando-se diferentes doses $(0,3 ; 0,5 ; 0,6 ; 1,0 ; 2,0 ; 3,0$; 5,$0 ;$ e 10,0 kGy) à polpa de tomate contendo resíduos dos quatro agrotóxicos (CARDOSO et al., 2008). Além disso, ampolas com a amostra fortificada, ampolas com a amostra branco e ampolas contendo soluções padrão na faixa de concentração correspondente à da amostra foram submetidas à radiação gama na dose de 2 kGy após serem seladas. Objetivando comparar os resultados, foram avaliadas paralelamente ampolas não irradiadas mantidas à temperatura ambiente. As condições de tempo e temperatura de estocagem foram iguais àquelas do Estudo piloto I, entretanto, os dois estudos não se iniciaram no mesmo dia devido à indisponibilidade do irradiador de alimentos.

\section{Preparo do material INCQS-MRC01}

Tal material foi preparado conforme apresentado por Cardoso (2008). O tratamento selecionado para manter a integridade da amostra foi a irradiação na dose de $2 \mathrm{kGy}$. Em seguida, as amostras foram mantidas em freezer até o momento de serem enviadas aos laboratórios ou submetidas a avaliações de acompanhamento durante o período de armazenamento.

\subsection{Fonte de irradiação}

As amostras foram submetidas à radiação gama em um irradiador de pesquisa do tipo cavidade blindada; com porta blindada e fonte móveis; dimensões aproximadas de $3 \times 2 \times 1,7 \mathrm{~m}$; fonte de ${ }^{137} \mathrm{Cs}$ com atividade de $46 \mathrm{kCi}$ e taxa de dose máxima de $1,8 \mathrm{kGy} \cdot \mathrm{h}^{-1}$, localizado no Centro Tecnológico do Exército - CTEx, Rio de Janeiro - RJ (VITAL et al., 2000; CARDOSO et al., 2008).

\subsection{Método multirresíduos e instrumentação analítica}

Para quantificação dos quatro agrotóxicos na polpa de tomate, empregou-se o procedimento descrito por Cardoso (2008).

\subsection{Estabilidade da estocagem}

A estabilidade do material foi avaliada nas seguintes condições de tempo e temperatura de armazenamento: em freezer $\left(-10 \mathrm{a}-25^{\circ} \mathrm{C}\right)$, geladeira $\left(4 \mathrm{a} 6^{\circ} \mathrm{C}\right)$, estufa $\left(38\right.$ a $\left.52^{\circ} \mathrm{C}\right)$ e temperatura ambiente $\left(20 \mathrm{a} 27^{\circ} \mathrm{C}\right)$, sendo que o período total de estocagem foi de um ano para as amostras submetidas ao processo de pasteurização e de 10 meses para as amostras irradiadas. Durante a estocagem foram feitas análises de monitoração semanais no primeiro mês, quinzenais no período posterior. Os resultados das concentrações determinadas pelo teste de homogeneidade referem-se ao dia zero. Cada amostragem (em duplicatas), nas condições estabelecidas, é acompanhada de dois brancos da amostra, duas amostras fortificadas no dia da análise e duas armazenadas sob as condições teste, ou seja, em 
freezer, geladeira, estufa e temperatura ambiente, totalizando 12 ensaios para cada período de estocagem.

As ampolas lacradas, contendo material submetido aos respectivos tratamentos, foram selecionadas aleatoriamente nos dias de realização do ensaio. Os agrotóxicos foram extraídos da amostra usando o método de multirresíduos, sendo que duas alíquotas do mesmo extrato, denominadas de replicatas A e B, foram analisadas por CG/DCE para quantificação. Os resultados apresentados correspondem à concentração média encontrada.

\section{Resultados e discussão}

As avaliações preliminares, objetivando determinar os efeitos dos referidos tratamentos à amostra, forneceram informações sobre a viabilidade do emprego de ambos os processos.

Para as amostras submetidas à pasteurização a $90{ }^{\circ} \mathrm{C}$ por 4 minutos, as taxas de recuperação encontradas para os resíduos de $\gamma-\mathrm{HCH}$, fenitrotiona, clorpirifós e procimidona foram de 86 , 70, 92 e 100\%, respectivamente. A indicação desta condição baseou-se em trabalho apresentado por Armishaw e Millar (2001).

Os resultados encontrados através do processo de irradiação, indicam a possibilidade de uso da dose de 2 kGy para a finalidade pretendida (CARDOSO et al., 2008).

O lote inicialmente preparado para os Estudos pilotos I e II permitiu avaliar previamente a integridade da amostra, após confirmação da homogeneidade, em relação ao tempo de estocagem sob diferentes temperaturas, após serem submetidas aos tratamentos de pasteurização e radiação.

Nas Tabelas 1 e 2 são apresentados os valores médios de concentração encontrados para cada agrotóxico na amostra submetidas aos processos de pasteurização e radiação gama, no dia do ensaio, durante o período garantido de integridade da amostra sob condições pré-definidas. São apresentados também os dados necessários à observação se a regressão linear apresenta alguma tendência durante o intervalo de tempo.

Os resultados da análise de variância utilizados para estimar a variância dos valores avaliados na regressão linear para o estudo de estabilidade do $\gamma-\mathrm{HCH}$ (após processo de pasteurização), estocado por 372 dias em freezer, estão mostrados na Tabela 3, segundo a International Organization For Standardization (2006) e na Figura 1 está representada graficamente a tendência destes resultados. Vale salientar que estas avaliações foram realizadas para cada um dos quatro agrotóxicos sob as diferentes condições de estocagem nos Estudos piloto I e II, entretanto, neste trabalho somente será apresentado o exemplo demonstrado na Tabela 3 e na Figura 1. Os valores necessários à comprovação da estabilidade para cada substância, obtidos através deste teste estatístico, encontram-se nas Tabelas 1 e 2 .

A avaliação estatística para testar a significância da regressão das concentrações dos agrotóxicos, na polpa de tomate, durante o intervalo de tempo estudado é observada através da aplicação do valor $\mathrm{P}$ da inclinação da regressão (indicado na linha do coeficiente da variável X 1). Caso o valor P seja maior que 0,05 (ao nível de confiança de 95\%), a inclinação da regressão linear é considerada insignificante.

A significância da inclinação da regressão, $b_{1}$, também pode ser estatisticamente testada através da aplicação do teste $t$ de "Student", para n - 2 graus de liberdade e $p=0,95$ (95\% o nível de confiança. Neste caso, se $\left|b_{1}\right|<\mathrm{t}_{(0,95, \mathrm{n}-2)}{ }^{*} s\left(b_{1}\right)$, indicará que o material tem estabilidade garantida, ou seja, a inclinação da regressão é insignificante (LINSINGER et al., 2001b; INTERNATIONAL ORGANIZATION FOR STANDARDIZATION, 2006). Os parâmetros $b_{1}$ (inclinação da linha de regressão, indicado como o coeficiente da variável X 1 ) e $s\left(b_{1}\right)$ (desvio padrão da inclinação, indicado como erro padrão da variável X 1) são apresentados na Tabela 3, obtidos pela função 'análise de regressão' do programa Windows/Excel ${ }^{\oplus}$.

Os resultados obtidos pelo tratamento estatístico dos dados gerados pelos Estudos pilotos I e II, conforme apresentados nas Tabelas 1 e 2, mostraram que todos os valores de $\mathrm{P}$ calculados (valor P) foram maiores que 0,05 , bem como, os valores de $\left|b_{1}\right|$, em todas as situações, foram menores que o valor de $\mathrm{t}_{(0,95, \mathrm{n}-2)}{ }^{*} s\left(b_{1}\right)$. Por conseguinte, os agrotóxicos estudados foram considerados estáveis nas condições de uso para o período de estabilidade apresentado nas Tabelas 1 e 2.

A partir da mesma tabela gerada com os dados da regressão e ANOVA, calcula-se a incerteza inerente à estabilidade multiplicando o valor do erro padrão da inclinação pelo tempo de estudo (expresso em dias), de acordo com a Equação 1.

$u_{\mathrm{est}}=$ erro padrão $\times$ tempo de estudo

Os brancos das amostras e as amostras fortificadas nos dias de cada experimento estavam de acordo com o perfil cromatográfico obtido na avaliação inicial da polpa de tomate e as taxas de recuperação situaram-se na faixa aceitável de 70 a $120 \%$ para os agrotóxicos nas concentrações estudadas (DG-SANCO, 2007), não apresentando indícios de falha no processo experimental em ambos os tratamentos aplicados.

Embora as amostras submetidas ao tratamento térmico de pasteurização tenham sido monitoradas durante um período mais longo, foi possível observar que as degradações das substâncias ocorreram em intervalos de tempo menores, quando comparadas àquelas amostras submetidas à irradiação gama, demonstrando ser este último tratamento mais indicado ao objetivo proposto. $\mathrm{O} \gamma-\mathrm{HCH}$, por exemplo, se manteve estável por 273 dias sob as diferentes condições de estocagem após irradiação. Este fato é esperado já que uma substância da classe dos organoclorados possui reconhecida estabilidade ao longo do tempo e que, provavelmente, não se degradaria sob tais condições.

Diante da preocupação de simular condições extremas durante o transporte do material, as medições isocrônicas indicaram que a fenitrotiona e a procimidona submetidas a temperaturas entre 38 a $52{ }^{\circ} \mathrm{C}$, durante o Estudo piloto I, mantiveram-se íntegras apenas durante o período de até 7 dias. Esta situação pode ser evitada, definindo condições ideais para 
o transporte do material. Nas amostras irradiadas no Estudo piloto II, apenas a procimidona apresentou sinais de degradação nas mesmas condições. Indícios de degeneração também foram achados após 14 dias na fenitrotiona das amostras não irradiadas, mantidas em temperatura ambiente $\left(20\right.$ a $\left.27^{\circ} \mathrm{C}\right)$.
A contribuição da incerteza referente ao curto tempo de estocagem (condições extremas) não será considerada (LINSINGER et al., 2001a), pois a amostra se manteve estável por períodos semelhantes nas demais condições indicadas, de acordo com as Tabelas 1 e 2.

Tabela 1. Concentrações médias obtidas para a estabilidade garantida após períodos pré-definidos de dias de estocagem para o $\gamma$-HCH, fenitrotiona, clorpirifós e procimidona na polpa de tomate (submetidas ao processo de pasteurização, Estudo piloto I).

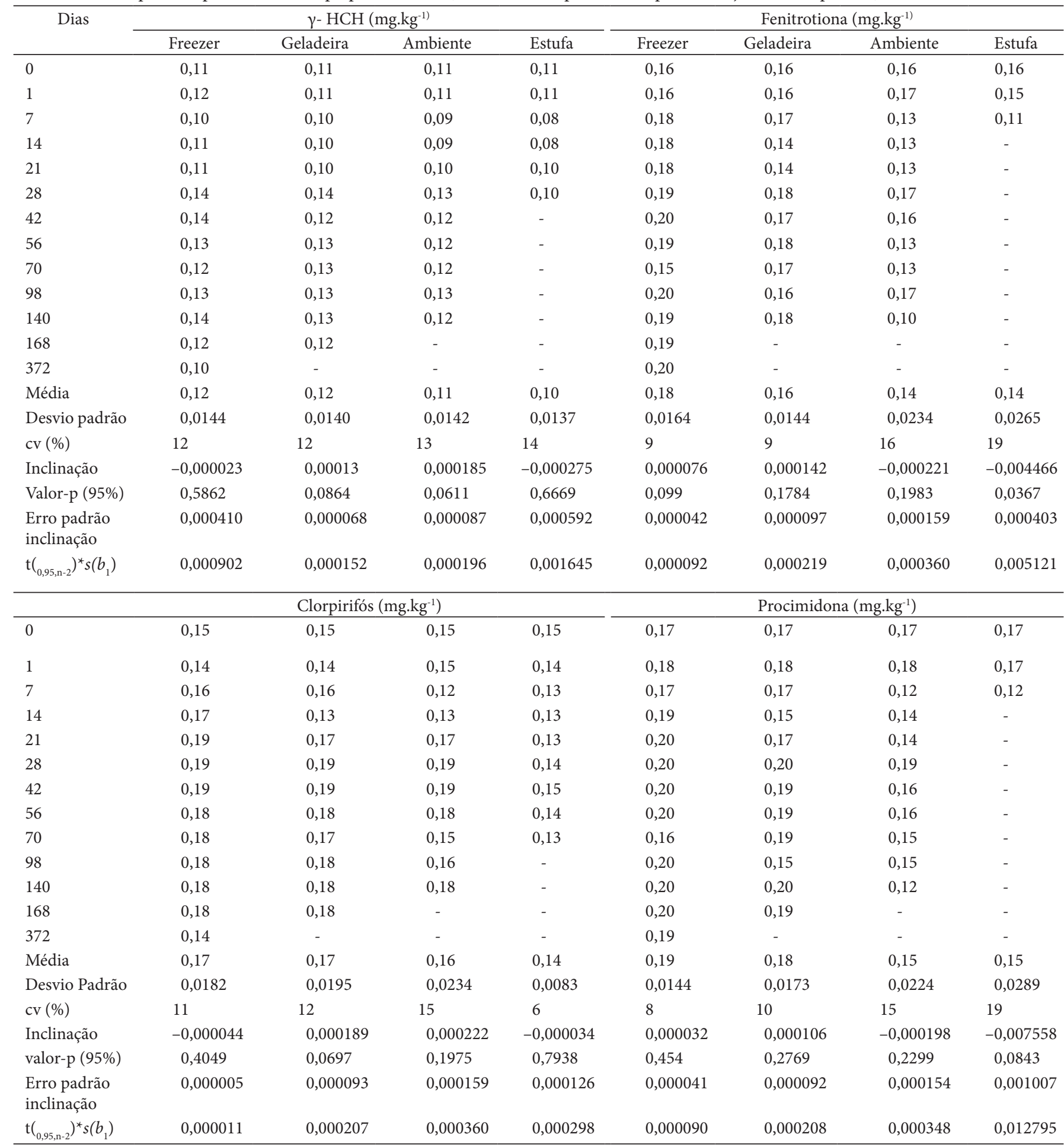

As faixas de temperaturas citadas na Tabela 1 correspondem a: freezer $\left(-10\right.$ a $\left.-25^{\circ} \mathrm{C}\right)$, geladeira $\left(4\right.$ a $\left.6{ }^{\circ} \mathrm{C}\right)$, estufa $\left(38\right.$ a $\left.52{ }^{\circ} \mathrm{C}\right)$ e temperatura ambiente $\left(20\right.$ a $\left.27^{\circ} \mathrm{C}\right)$; e os valores da inclinação, valor-p (95\%) e erro padrão da inclinação $-s\left(b_{1}\right)$, foram obtidos a partir da regressão linear dos dados indicados na Tabela 1 . 
Tabela 2. Concentrações médias obtidas para a estabilidade garantida após períodos pré-definidos de dias de estocagem para o $\gamma$-HCH, fenitrotiona, clorpirifós e procimidona na polpa de tomate (submetidas ao processo de radiação gama, Estudo piloto II).

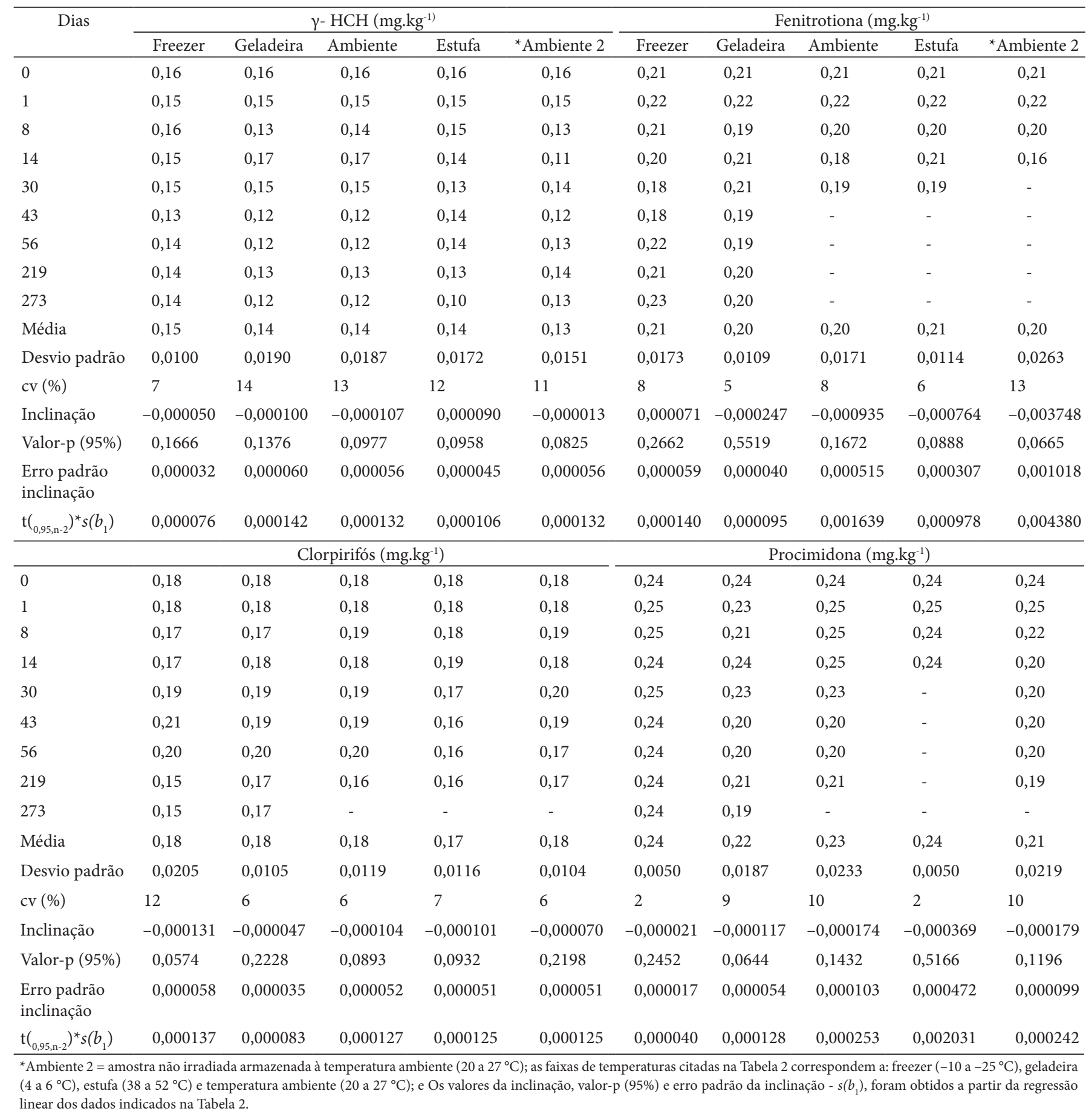

Para obter-se a incerteza associada à estabilidade, buscou-se o critério clássico, do longo tempo de estocagem, ou seja, o valor do erro padrão obtido no experimento, conduzido em freezer $\left(-10\right.$ a $\left.-25^{\circ} \mathrm{C}\right)$, foi multiplicado pelo tempo de estocagem, conforme a Equação 1.

$\mathrm{Na}$ Tabela 4, são apresentados os valores das incertezas referentes à estabilidade ao longo do tempo de estocagem da amostra candidata à material de referência. Os cálculos foram feitos usando-se a Equação 1 para os quatro agrotóxicos estudados, com dados das Tabelas 1 e 2.

Diante dos resultados obtidos, preparou-se o material INCQS-MRC01 com base nos dados gerados nos testes prévios de estabilidade das amostras tratadas por radiação gama na dose de $2 \mathrm{kGy}$.

Embora o estudo de estabilidade tenha ocorrido durante 372 e 273 dias para os tratamentos de pasteurização e irradiação 


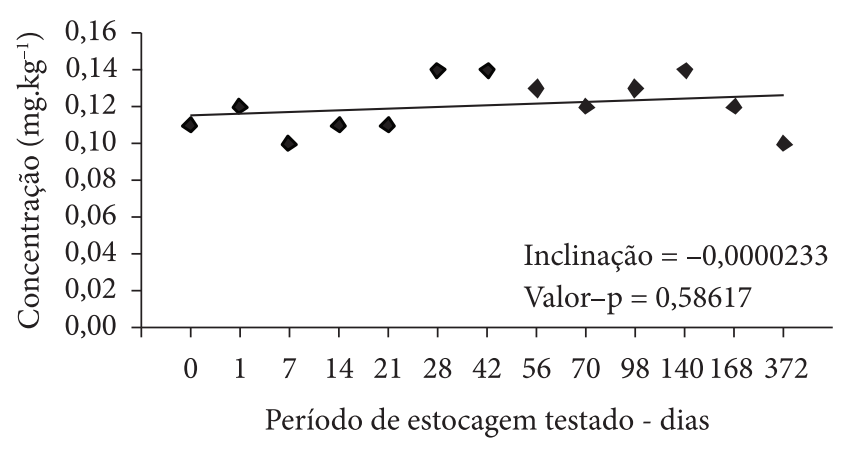

Figura 1. Gráfico da análise de regressão dos resultados médios das concentrações do agrotóxico $\gamma-\mathrm{HCH}$, nas amostras submetidas ao processo de pasteurização do Estudo piloto I ( $90^{\circ} \mathrm{C}$ por 4 minutos) após 372 dias de estocagem em freezer $\left(-10 \mathrm{a}-25^{\circ} \mathrm{C}\right)$.

Tabela 3. Análise de regressão para o agrotóxico $\gamma-\mathrm{HCH}$, na polpa de tomate submetida ao processo de pasteurização (Estudo piloto I), após período de estocagem de 372 dias em freezer $\left(-10 \mathrm{a}-25^{\circ} \mathrm{C}\right)$.

\begin{tabular}{|c|c|c|c|c|c|c|}
\hline \multicolumn{7}{|c|}{ Estatística de regressão para o $\gamma-\mathrm{HCH}$} \\
\hline \multicolumn{2}{|l|}{ R múltiplo } & \multicolumn{5}{|c|}{0,16672467} \\
\hline \multicolumn{2}{|l|}{ R-quadrado } & \multicolumn{5}{|c|}{0,02779711} \\
\hline \multicolumn{2}{|c|}{ R-quadrado ajustado } & \multicolumn{5}{|c|}{$-0,06058497$} \\
\hline \multicolumn{2}{|c|}{ Erro padrão } & \multicolumn{5}{|c|}{0,01484168} \\
\hline \multicolumn{2}{|l|}{ Observações } & \multicolumn{5}{|c|}{13} \\
\hline \multicolumn{7}{|l|}{ ANOVA } \\
\hline & $\mathrm{gl}$ & & Q & & MQ & $\mathrm{F}$ \\
\hline Regressão & 1 & & 000693 & 0,0 & 000693 & 0,3145107 \\
\hline Resíduo & 11 & & 024230 & 0,0 & 0022028 & \\
\hline \multirow[t]{2}{*}{ Total } & 12 & & 024923 & & & \\
\hline & \multicolumn{2}{|c|}{ Coeficientes } & \multicolumn{2}{|c|}{ Erro padrão } & Start t & Valor-P \\
\hline Interseção & \multicolumn{2}{|c|}{0,1225926} & \multicolumn{2}{|c|}{0,0052455} & 23,37082 & $9,992 \mathrm{E}-11$ \\
\hline $\begin{array}{l}\text { Variável X } 1 \\
\text { (inclinação) }\end{array}$ & \multicolumn{2}{|c|}{$-0,0000233$} & \multicolumn{2}{|c|}{0,0000416} & $-0,56081$ & 0,5861671 \\
\hline
\end{tabular}

Tabela 4. Incerteza padrão calculada para os agrotóxicos $\gamma-\mathrm{HCH}$, fenitrotiona, clorpirifós e procimidona pelos tratamentos de pasteurização e radiação gama.

\begin{tabular}{lcc}
\hline \multirow{2}{*}{ Agrotóxico } & \multicolumn{2}{c}{ Incerteza padrão $\left(u_{\text {ess }}\right)\left(\mathrm{mg}^{\mathrm{k}} \mathrm{kg}^{-1}\right)$} \\
\cline { 2 - 3 } & \multicolumn{2}{c}{ Tratamento } \\
\cline { 2 - 3 } & Pasteurização (372 dias) & Irradiação gama (273 dias) \\
\hline$\gamma$-HCH & 0,015 & 0,009 \\
Fenitrotiona & 0,016 & 0,016 \\
Clorpirifós & 0,019 & 0,016 \\
Procimidona & 0,015 & 0,005 \\
\hline
\end{tabular}

gama, respectivamente, uma extrapolação permite uma estimativa para o futuro, tendo em vista que a estabilidade observada durante esses períodos não asseguraria a priori a estabilidade nos períodos vindouros. Por conseguinte, a rigor, o INCQS-MRC01, deverá ter sua estabilidade monitorada também ao longo do período de estocagem (LINSINGER et al., 2001b).

\section{Conclusões}

Conclui-se que os quatro agrotóxicos analisados $(\gamma-\mathrm{HCH}$, fenitrotiona, clorpirifós e procimidona, adicionados à polpa de tomate na faixa de concentração de 0,1 a $0,2 \mathrm{mg} \cdot \mathrm{kg}^{-1}$ ), tratados por pasteurização ou irradiação, mantiveram-se estáveis durante os períodos de monitoração nas condições de armazenamento em freezer $\left(-10 \mathrm{a}-25^{\circ} \mathrm{C}\right), 372$ e 273 dias, respectivamente. No entanto, as variações indicativas de instabilidade foram menores no tratamento por irradiação com dose de $2 \mathrm{kGy}$, sugerindo uma preferência para a seleção desse processo na produção de material de referência.

\section{Agradecimentos}

À Financiadora de Estudos e Projetos - FINEP, pelos auxílios financeiros concedidos ao projeto "Estruturação de uma rede de laboratórios de análise de resíduos de agrotóxicos para apoio à exportação de alimentos (REAGROEX)".

\section{Referências bibliográficas}

ARMISHAW, P.; MILLAR, R. A natural matrix (pureed tomato) candidate reference material containing residue concentrations of pesticide chemicals. Fresenius Journal Analytical Chemistry, v. 370, p. 291-296, 2001.

BRASIL. Ministério da Saúde. Agência Nacional de Vigilância Sanitária. Resolução - RDC n 21, 26 de janeiro de 2001. Diário Oficial da União. Disponível em: < http://www.anvisa.gov.br/legis/ resol/21_01rdc.htm>. Acesso em: 23 fev. 2008.

BRASIL. Ministério do Desenvolvimento, Indústria e Comércio Exterior. Instituto Nacional de Metrologia, Normalização e Qualidade Industrial - INMETRO. Vocabulário internacional de termos fundamentais e gerais de metrologia (VIM). 5. ed. Rio de Janeiro: SENAI, 2007.

CARDOSO, M. H. W. M. Preparação de um material de referência certificado para controle de agrotóxicos em hortifrutigranjeiros. 2008. 191 p. Tese (Doutorado) - Instituto Nacional de Controle de Qualidade em Saúde, Fundação Oswaldo Cruz, Rio de Janeiro, 2008.

CARDosO, M. H. W. M. et al. Aplicação da radiação gama na preservação de material de referência a ser usado na análise de resíduos de agrotóxicos. Analytica, v. 36, p. 64-69, 2008.

COUTINHO, C. F. B. et al. Pesticidas: mecanismo de ação, degradação e toxidez. Pesticidas: Revista de Ecotoxicologia e Meio Ambiente, v. 15, p. 65-72, 2005.

DG-SANCO - EUROPEAN COMISSION. Method validation and quality control procedures for pesticide residues analysis in food and feed. Brussels: SANCO, 2007. Document 3131.

FLORES, A. V. et al. Organoclorados: um problema de saúde pública. Ambiente \& Sociedade, v. 7, n. 2, p. 125-143, 2004.

GAVA, A. J. Métodos de conservação de alimentos. In: GAVA, A. J. Princípios de tecnologia de alimentos. São Paulo: Nobel, 1999.

INTERNATIONAL ORGANIZATION FOR STANDARDIZATION. Reference materials: general and statistical principles for certification. Switzerland: ISO, 2006. Guide 35.

LAMBERTY; A.; SCHIMMEL, H.; PAUWELS, J. The study of the stability of reference materials by isochronous measurements. Fresenius Journal Analytical Chemistry, v. 360, p. 359-361, 1998. 
LINSINGER, T. P. J. et al. Estimating the uncertainty of stability for matrix CRMs. Fresenius Journal Analytical Chemistry, v. 370, p. 183-188, 2001a.

LINSINGER, T. P. J. et al. Homogeneity and stability of reference materials. Accreditation and Quality Assurance, v. 6, p. 20-25, $2001 \mathrm{~b}$.

LINSINGER, T. P. J. et al. Planning and combining of isochronous stability studies of CRMs. Accreditation and Quality Assurance, v. 9, p. 464-472, 2004.

MARTINS, E. L. Previsão da lixiviação de pesticidas utilizados na cultura de algodão em Mato Grosso. 2006. $82 \mathrm{f}$. Dissertação (Mestrado) - Universidade Federal do Mato Grosso, Cuiabá, 2006.

SILVA, A. C. O. et al. Radiação em alimentos. uma revisão. Higiene Alimentar, v. 20, p. 17-23, 2006.
SINGH, B. K. et al. Microbial degradation of the pesticide lindane ( $\gamma$-hexachlorocyclohexane). Advances in Applied Microbiology, v. 47, p. 269-298, 2000.

SANT'ANA, A. S.; ARAÚJO, I. O. Irradiação e a segurança e qualidade microbiológica dos alimentos. Higiene Alimentar, v. 21, p. 37-51, 2007.

van der VEEN, A. M. H et al. Uncertanty calculations in the certification of reference materials 3: stability study. Accreditation and Quality Assurance, v. 6, p. 257-263, 2001.

VITAL, H. C. et al. Experimentos dosimétricos no irradiador gama do IPE. In: ENCONTRO NACIONAL DE APLICAÇÕES NUCLEARES, 5., 2000, Rio de Janeiro. Anais... Rio de Janeiro: ENAN, 2000. p. 15-20. 